\title{
Contrasting morphological evidence for the presence of taste buds in Dromaius novaehollandiae and Struthio camelus (Palaeognathae, Aves)
}

\author{
Martina Rachel Crole \\ Department of Anatomy and Physiology, Faculty of Veterinary Science, University of Pretoria, \\ martina.crole@up.ac.za \\ John Thomson Soley \\ Department of Anatomy and Physiology, Faculty of Veterinary Science, University of Pretoria
}

\begin{abstract}
This study, facilitated by the use of immunohistochemistry, indicated the presence of taste buds in Dromaius novaehollandiae but not in Struthio camelus. Seen at the light microscope level, the taste buds consisted of follicular cells and receptor cells. The follicular cells were located at the periphery of the taste bud, essentially encapsulating the receptor cells. Two morphologically distinct receptor cells were identified. Immunohistochemical labelling for neurofilament identified gustatory nerves within the taste bud. The distribution of taste buds in $D$. novaehollandiae matched strategic locations in the oropharynx along which food could be sampled, according to the feeding method described for these birds. Future feeding studies would be necessary in $D$. novaehollandiae to determine the importance of taste discrimination in their diet. This study represents the first confirmed report of a sense of taste in any ratite species.
\end{abstract}

\section{Keywords}

Morphology Nerve fibres Palaeognathae Ratite Taste buds

\section{Introduction}

The sense of taste in birds is an important motivator for feeding as well as initial food selection (Gentle 1971a). However, food selection is also based on size, shape, colour and texture (Berkhoudt 1985) as well as a combination of taste and olfaction (Gerritsen et al. 1983; van Heezik et al. 1983; Berkhoudt 1985). Birds possess a limited number of taste buds in comparison with other vertebrates (Berkhoudt 1985; Ganchrow and Ganchrow 1985; Brand and Gous 2006; Roura et al. 2013), and due to their different eating habits and diets, their presence or absence in the avian oropharynx has been heavily debated (Moore and Elliott 1946). However, despite the reported low number of taste buds, birds do possess an acute sense of taste (Berkhoudt 1985; Roura et al. 2013). Taste buds have been positively identified in numerous avian species (Bath 1906; Botezat 1910; Warner et al. 1967; Berkhoudt 1985) including domestic poultry (Lindenmaier and Kare 1959; Saito 1966; Gentle 1971b; Berkhoudt 1977; Kurosawa et al. 1983; Ganchrow and Ganchrow 1985, 
1987, 1989; Kudo et al. 2008; Roura et al. 2013), of which Gallus domesticus (Linnaeus 1758) has been most extensively researched.

Conclusive evidence of a sense of taste in ratites has remained elusive. Various investigations have yielded negative results in both Struthio camelus (Linnaeus 1758) (Brand and Gous 2006; Jackowiak and Ludwig 2008; Tivane 2008) and Rhea americana (Linnaeus 1758) (Feder 1972; Santos et al. 2011). However, in Dromaius novaehollandiae (Latham 1790), a structure resembling a taste bud was identified in the tongue root (Crole and Soley 2009) and, although not positively confirmed as such, was suggestive of a sense of taste in ratite species. McCann (1973) interpreted openings in Apteryx spp. oropharynx as 'taste pores'. However, it is more probable that the pores represent the openings of underlying glands, as no histological evidence of taste buds was supplied. Ratite species swallow their food whole, employing the 'catch and throw' (Gussekloo and Bout 2005) or cranioinertial feeding method (Bonga Tomlinson 2000), in which the food lands near or within the oesophageal entrance prior to swallowing. As a result of this method of food intake, there would be a limited need or opportunity for taste during the intra-oral transport of food. It would thus seem appropriate that any taste receptors found in the oropharynx would be sparse and located in the more caudal regions of the oropharynx.

In view of the lack of convincing evidence on the presence of taste receptors in the ratite oropharynx, this study aimed to examine this region in two commercially exploited ratite species, $D$. novaehollandiae and $S$. camelus, to determine whether taste buds could be identified in either species. Use was made of conventional light microscopy stains as well as immunohistochemical (IHC) labelling for neurofilament protein. In the event of confirming the presence of taste buds, the study further aimed to describe their basic distribution and light microscopic structure and compare the results with information on avian taste buds in general. At a practical level, knowledge of a sense of taste in $D$. novaehollandiae and $S$. camelus may have an impact on the composition of their feed rations as well as providing a more holistic view on food selection. The terminology used is that of Nomina Anatomica Avium (Baumel et al. 1993).

\section{Materials and methods}

A total of 10 adult $S$. camelus and 15 adult $D$. novaehollandiae heads, from birds of either sex, were collected after slaughter from the Klein Karoo Ostrich abattoir (Oudtshoorn, Western Cape, South Africa) and Oryx Abattoir (Krugersdorp, Gauteng, South Africa), respectively. All heads were thoroughly rinsed with running tap water to remove mucus, blood and regurgitated food. The heads were immersion fixed in $10 \%$ neutral-buffered formalin and transported to the Faculty of Veterinary Science, University of Pretoria. Formalin contact with all parts of the oropharynx was ensured by wedging the bill open with a small block of wood before immersing the heads in fixative. 


\section{Light microscopy}

\section{Distribution of taste buds}

Samples representing all regions of the oropharynx and the proximal oesophagus were taken from one half of ten $D$. novaehollandiae and five $S$. camelus heads to determine the presence/distribution of taste buds (Fig. 1). The oropharynx was exposed as previously described (Crole and Soley 2010a). The interramal region was removed from the bony mandible by sharp incision following the inside mandibular edge. As the epithelium was difficult to remove from the underlying bone, the rostral portion of the maxilla (removed with a band-saw) and the mandible were decalcified prior to further processing of the tissue from these regions (labelled $\mathrm{Rr}$ and $\mathrm{M}$ in Fig. 1) for light microscopy. Decalcification of the premaxillae and mandibles took place over a period of 6 weeks in an $8 \%$ formic acid solution. The samples were placed in a fresh solution fortnightly. Appropriate segments of the mucosa representing all remaining parts of the oropharynx were removed from the regions indicated in Fig. 1. Each segment, as well as the decalcified premaxilla and mandible, was cut into smaller pieces by hand in the transverse plane at approximately $5-\mathrm{mm}$ intervals, dehydrated through a graded ethanol series and further processed through 50:50 ethanol: xylol, 2X xylol and 2X paraffin wax (60120 min per step) using a Shandon model 2LE Automatic Tissue Processor (Shandon, Pittsburgh, PA, USA). Tissue samples were then manually imbedded into paraffin wax in plastic moulds. Sections were cut at 4-6 $\mu \mathrm{m}$ and stained with haematoxylin and eosin (H\&E) (Bancroft and Gamble 2002). Histological sections were viewed, and features of interest described and digitally recorded using an Olympus BX63 light microscope (Olympus Corporation, Tokyo, Japan) equipped with a DP72 camera and Olympus cellSens imaging software (Olympus Corporation, Tokyo, Japan).
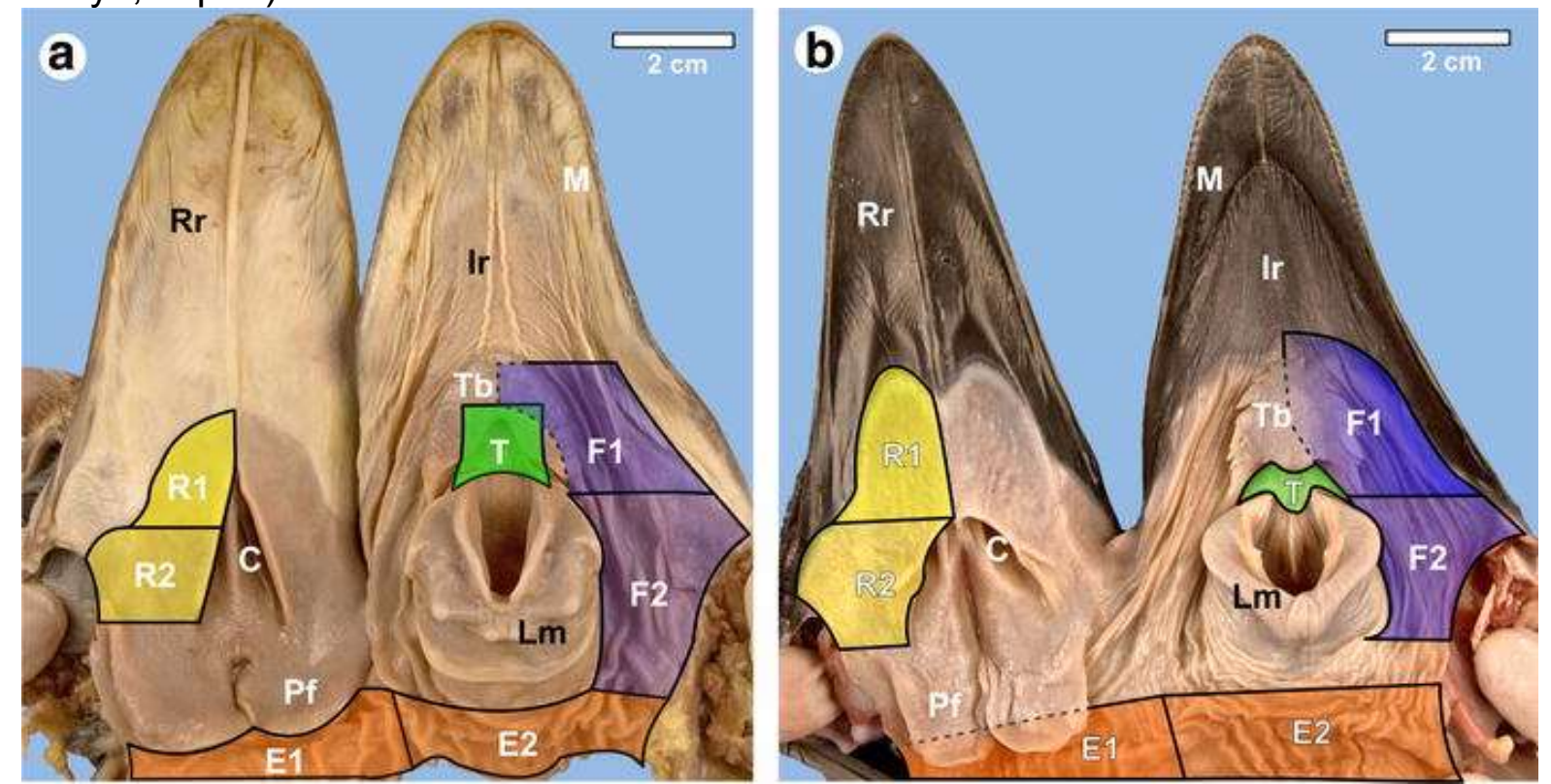

Fig. 1 : S. camelus (a) and D. novaehollandiae (b) head opened to display the regions of the oropharynx sampled to determine the presence/distribution of taste buds. Shading represents regions where taste buds were located in $D$. novaehollandiae, which were sampled at a higher frequency in both species. Rostral (F1) and caudal (F2) part of non-keratinised floor, tongue root ( $T$ ), dorsal oesophagus $(E 1)$, ventral oesophagus $(E 2)$, rostral $(R 1)$ and caudal $(R 2)$ part of non-keratinised roof, rostral aspect (keratinised) of the oropharyngeal roof $(R r)$, choana $(C)$, pharyngeal folds $(P f)$, mandible $(M)$, interramal region $(I r)$, tongue body $(T b)$ and laryngeal mound $(L m)$ 


\section{Taste bud morphology}

Based on the examination of the samples described above, the regions of the oropharynx identified to contain taste buds in $D$. novaehollandiae, as well as the proximal oesophagus, were again sampled (as previously described) in the remaining five $D$. novaehollandiae and five $S$. camelus heads, which had remained fixed in $10 \%$ neutral-buffered formalin for a maximum of 4 days. The non-keratinised roof and non-keratinised floor of the oropharynx, the tongue root and the proximal oesophagus (Fig. 1) were excised and then serially sectioned in the transverse plane at approximately 2- to 3-mm intervals. The samples were prepared for light microscopy and examined as detailed above.

\section{Immunohistochemistry}

Wax blocks corresponding to microscopy sections containing taste buds in $D$. novaehollandiae as well as blocks from comparable regions in $S$. camelus were carefully mounted and re-cut at $4 \mu \mathrm{m}$. The first few sections were mounted on positively charged microscope slides (SuperFrost ${ }^{\circledR}$ Plus, Menzel-Glasser ${ }^{\circledR}$ ) and dried overnight in a $38-40^{\circ} \mathrm{C}$ oven. Following routine dewaxing and rehydration, the sections were processed for $\mathrm{IHC}$ labelling for neurofilament protein to identify nerve fibres supplying the taste buds. The method followed was the same as that described in Crole et al. (2015). A monoclonal mouse anti-human neurofilament protein antibody (catalogue number M0762, Dako, Denmark) was used as primary antibody. A positive tissue control of ostrich spinal cord, liver and emu cartilaginous nasal septum with adjacent branch of the trigeminal nerve was treated with the above-mentioned antibody and immunodetection method. Negative reagent controls for these tissues, including those of the oropharynx, involved replacing the primary antibody with phosphate-buffered saline/bovine serum albumin buffer solution. A monoclonal mouse anti-human smooth muscle actin antibody (clone 1A4) (Code Number M0851, Dako, Denmark) was used as an irrelevant mouse monoclonal antibody control. Polyclonal rabbit anti-S100 antibody (Code Number Z0311, Dako, Denmark) served as an additional neuro-positive antibody control. Processing of all samples for immunohistochemistry was performed according to the manufacturer's instructions

\section{Results}

Taste buds (Caliculus gustatorius) were only identified in $D$. novaehollandiae, and no structures resembling taste buds were found in S. camelus with H\&E staining or IHC labelling (see below).

\section{Distribution}

Taste buds in $D$. novaehollandiae were identified caudally in the non-keratinised portion of the oropharynx and were located in the non-pigmented oropharyngeal roof (Figs. 2, 3), caudal oropharyngeal floor (Fig. 4) and proximal oesophagus, corresponding to the regions labelled R1, R2, F2, E1 and E2 in Fig. 1b. The highest concentration of taste buds occurred in the rostral part of the non-pigmented oropharyngeal roof, sandwiched between the caudo-lateral extension of the pigmented part of the roof and the choana (Fig. 1b, regions R1 and R2). Most of the 
taste buds were located adjacent to the openings of the large, simple branched tubular mucus-secreting glands (Fig. 2) typically present in the non-pigmented regions of the oropharynx, forming the Gl. palatina (Crole and Soley 2011). In the proximal oesophagus, where only simple tubular mucus-secreting glands [GIl. esophageales (Crole and Soley 2011)] were present, taste buds were isolated in the epithelium.

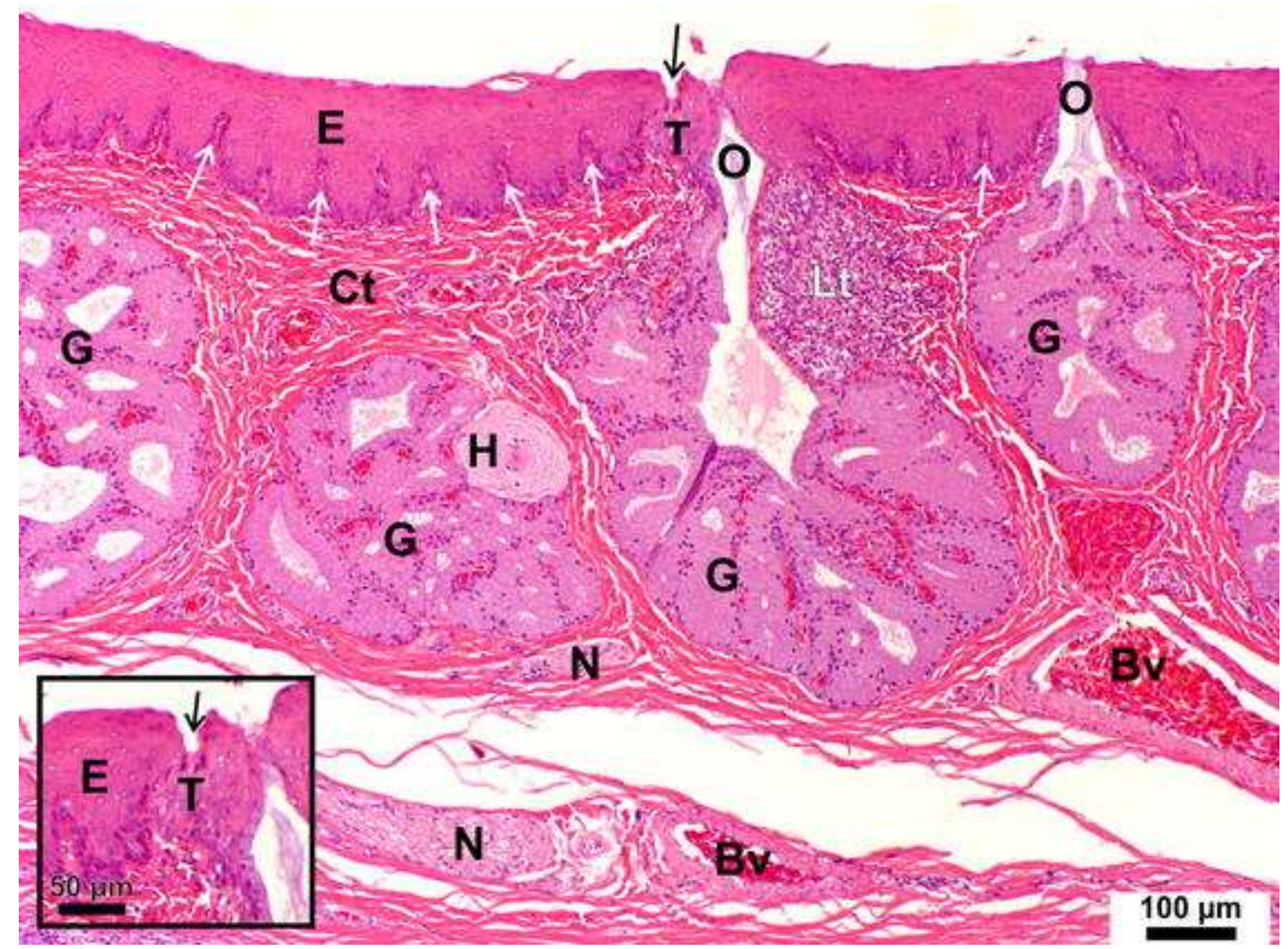

Fig. 2 : Taste bud $(T)$ located adjacent to the opening $(O)$ of a large, simple branched tubular gland $(G)$ in the non-pigmented roof of the oropharynx. Taste pore (black arrow), non-keratinised stratified squamous epithelium $(E)$, connective tissue papillae (white arrows), connective tissue $(C t)$, Herbst corpuscle $(H)$, blood vessel $(B v)$, nerve $(N)$ and lymphoid tissue $(L t)$. Inset enlargement of the taste bud. Haematoxylin and eosin-stained section 


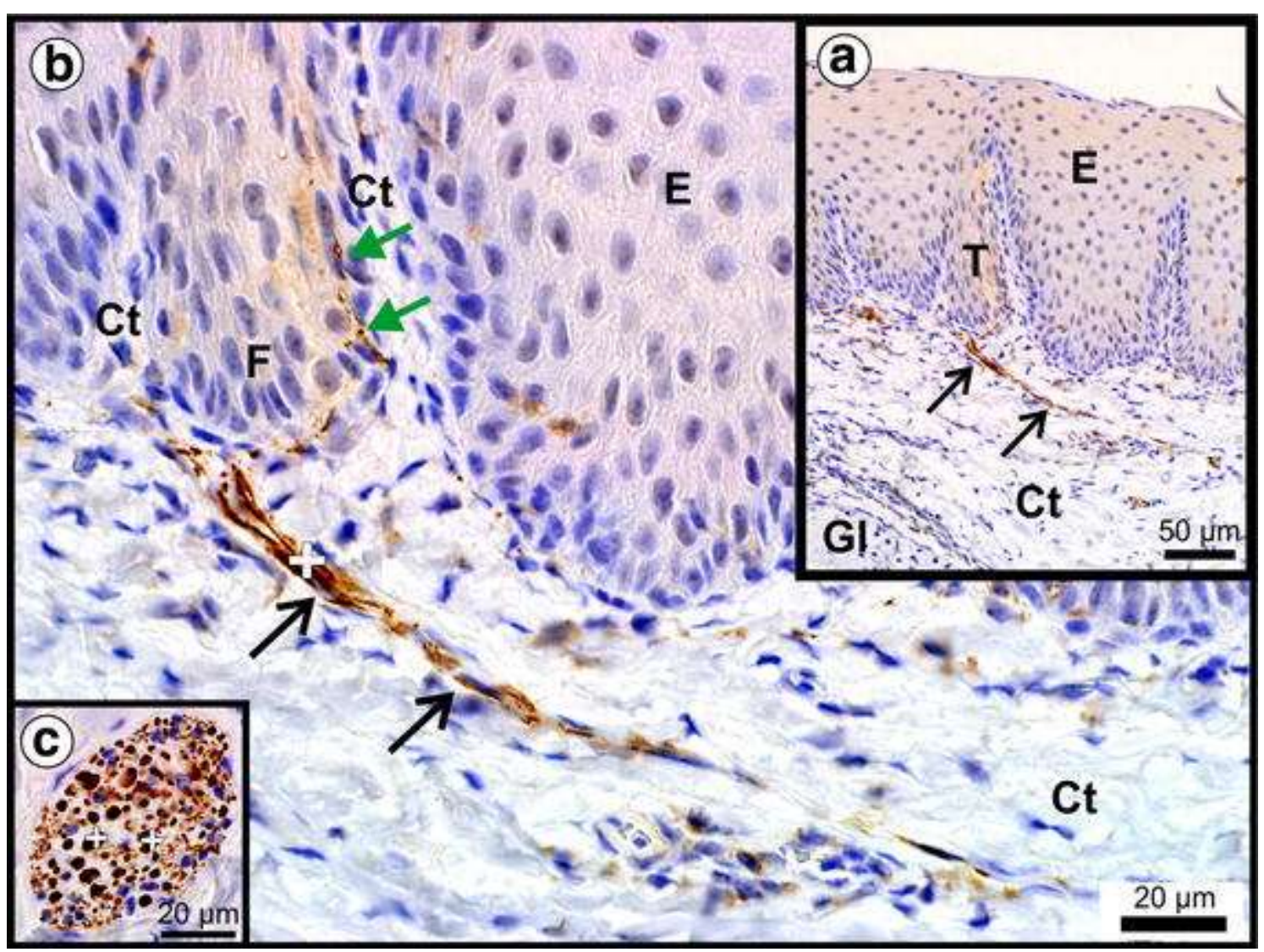

Fig. 3 : a and enlarged in b. Positive (plus) immunohistochemical labelling for neurofilament at the base of a presumptive taste bud from the non-pigmented oropharyngeal roof (region R1 in Fig. 1b) in $D$. novaehollandiae. The taste bud $(T)$ has been sectioned superficially, and mainly follicular cells $(F)$ can be seen. The subgemmal (black arrows) and perigemmal (green arrows) divisions of the gustatory nerve fibres are clearly demonstrated by the brown staining reaction. Non-keratinised stratified squamous epithelium (E), connective tissue (Ct) and gland (Gl). c Positive (plus) immunohistochemical labelling for neurofilament in a peripheral nerve in the surrounding connective tissue in the non-pigmented roof 


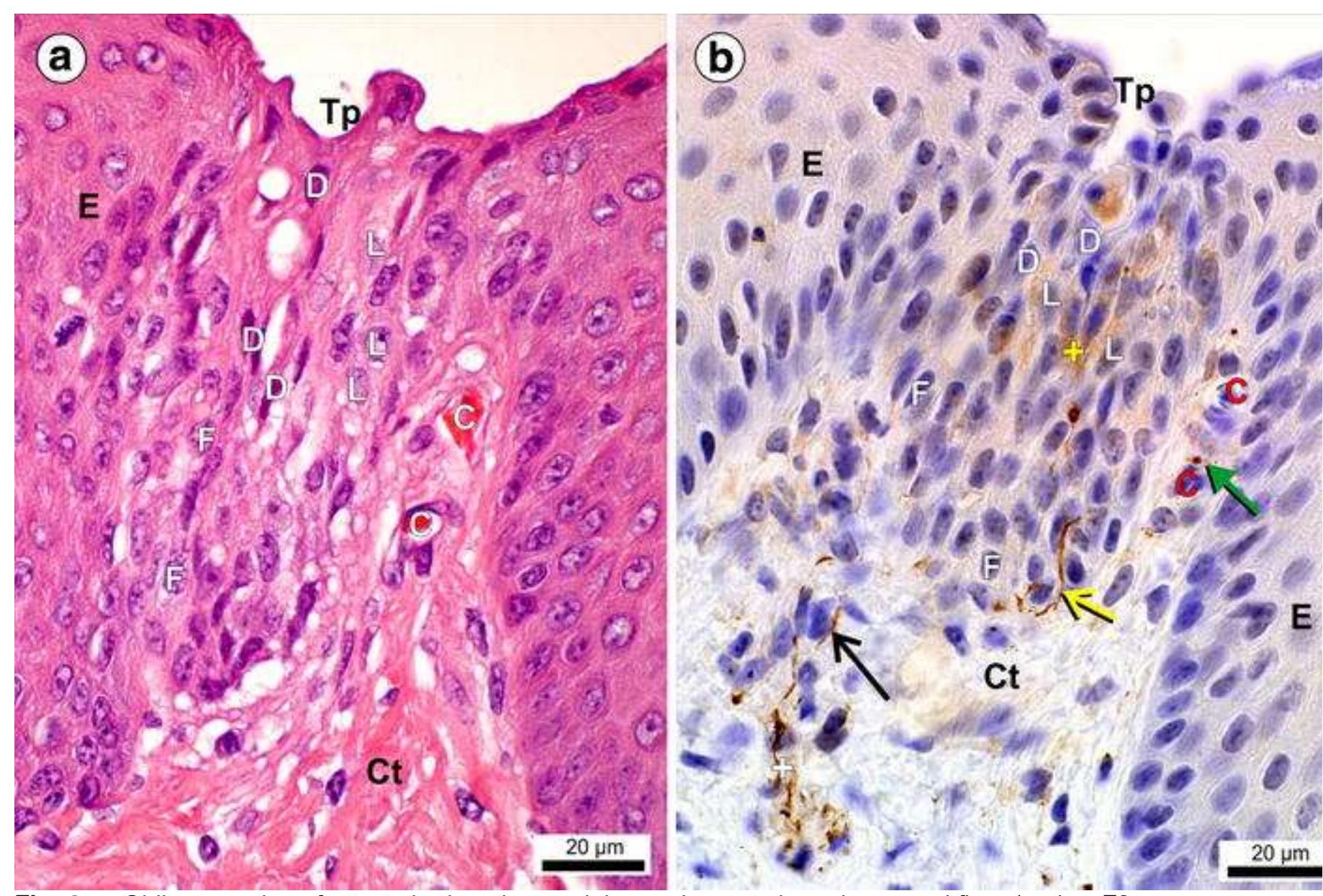

Fig. 4 : a Oblique section of a taste bud on the caudal non-pigmented oropharyngeal floor (region F2 in Fig. 1b) in $D$. novaehollandiae (haematoxylin and eosin staining). Dark cells $(D)$, light cells $(L)$, follicular cells $(F)$, taste pore $(T p)$, stratified squamous epithelium $(E)$, capillary $(C)$ and connective tissue $(C t)$. b Adjacent section of the same taste bud illustrated in Fig. 4a demonstrating positive (white plus) immunohistochemical labelling for neurofilament. Division of the gustatory nerve fibre into subgemmal (black open arrow), perigemmal (closed arrow) and intragemmal (yellow open arrow) fibres is obvious using this technique but indistinguishable with H\&E staining (Fig. 4a). The light cells show a diffuse positive (yellow plus) immunohistochemical labelling for neurofilament. Dark cells $(D)$, light cells $(L)$, follicular cells $(F)$, taste pore $(T p)$, stratified squamous epithelium $(E)$, capillary $(C)$ and connective tissue $(C t)$

\section{Structure}

The taste buds in $D$. novaehollandiae extended the full depth of the epithelium in which they were located (Figs. 2, 5). They were mostly teardrop-shaped (Fig. 5), although, depending on the plane of sectioning, they could also appear as round (Fig. 2), elliptical (ovoid) (Fig. 4) or rectangular (Fig. 3) structures. The proximal twothirds of the taste bud were surrounded by a layer of connective tissue which showed a similar composition to that of the adjacent connective tissue papillae. The connective tissue sheath surrounding the taste buds extended deeper into the epithelium than the papillae, carried capillaries at the distal extremity (Fig. 5) and, as demonstrated with positive IHC labelling for neurofilament (see below), contained many fine nerve fibres (perigemmal fibres) (Figs. 3, 4b). Due to variations in the plane of sectioning, it was not possible to accurately measure every taste bud. Based on a total of nine 'usable' taste buds and calculated to the nearest round 
number, the average height and width of these structures were $96 \pm 15$ and $51 \pm 7 \mu \mathrm{m}$, respectively.

The taste buds were composed of receptor cells and follicular cells. Two morphologically distinct receptor cells were identified (Figs. 4, 5). These cells were oriented vertically, projected into the taste pore via slender cytoplasmic processes and were situated as a group in the centre of the taste bud, surrounded by the follicular cells (Figs. 4,5). The more light staining receptor cells were rounded and displayed a large, pale-staining nucleus with a prominent nucleolus, whereas the darker receptor cells were slender, elongated components in which the nucleus was not always visible (Figs. 4,5). The follicular cells were continuous with the surrounding Stratum germinativum of the stratified squamous epithelium and formed the outer layer of the taste bud (Fig. 5). The taste pore (Porus gustatorius) (Figs. 4, $5)$ displayed a wider outer part $(25 \pm 3 \mu \mathrm{m})(n=9)$ which was formed by a depression in the epithelium and a narrower inner pore $(10 \pm 4 \mu \mathrm{m})(n=9)$ into which the receptor cells opened directly (Fig. 5). The taste pore was mostly filled with basophilic mucus. Round openings between the receptor cells appeared to represent taste canals (Fig. 5) in transverse section. Taste canals were not visible in all taste bud sections.

In D. novaehollandiae, specimens labelling positive for neurofilament (Figs. 3, 4b, 5) demonstrated numerous fine nerve fibres (Neurofibra gustatoria) at the base of the taste bud (subgemmal fibres) (Figs. 3, 4b, 5), within the connective tissue immediately surrounding the taste bud (perigemmal fibres) (Figs. 3, 4b, 5) and woven between the follicular and receptor cells (intragemmal fibres) (Figs 3, 4b, 5). The specificity of the neurofilament protein immunolabelling was confirmed by the staining properties of the various positive and negative tissue and reagent controls in the tissues examined.

The absence of taste buds in $S$. camelus material was confirmed by immunohistochemistry. Although the slides did demonstrate positive labelling for neurofilament in peripheral nerves and axons of Herbst corpuscles, there was no evidence of sub-, peri- and intragemmal nerve fibres associated with epithelial specialisations indicating the presence of taste buds in this species. 


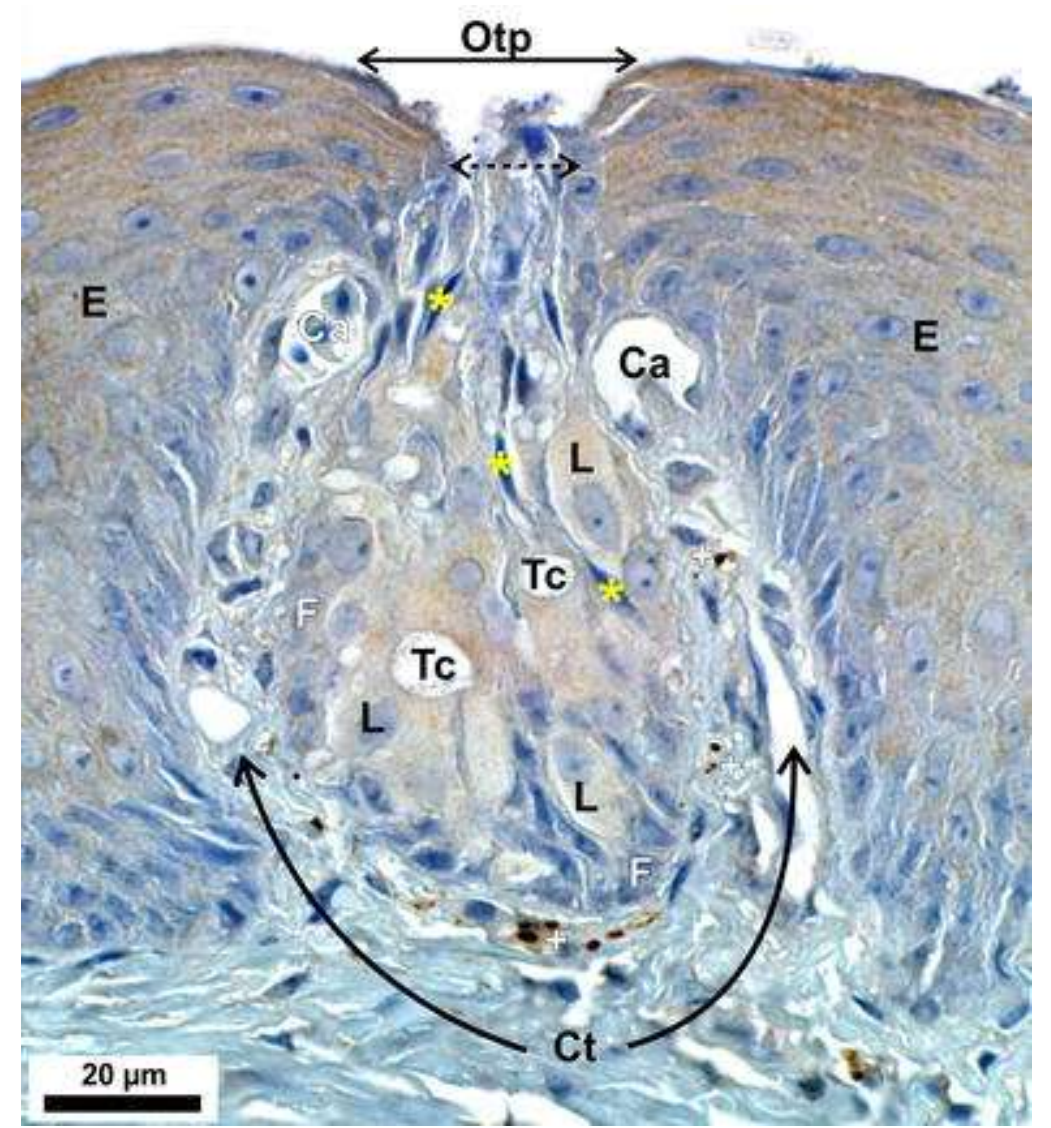

Fig. 5 : Taste bud in the caudal non-pigmented oropharyngeal roof (region $R 2$ in Fig. 1b) in $D$. novaehollandiae demonstrating positive (white plus) immunohistochemical labelling for neurofilament. Note the connective tissue $(\mathrm{Ct})$ which encapsulates the taste bud and carries capillaries $(\mathrm{Ca})$ distally. Dark cells (yellow asterisk), light cells $(L)$, follicular cells $(F)$, outer taste pore (Otp), inner taste pore (dotted double-headed arrow), taste canal (TC) and non-keratinised stratified squamous epithelium $(E)$. The degree of non-specific staining demonstrated by the surrounding epithelial cells would appear to reflect the long storage of this particular specimen in formalin

\section{Discussion}

Despite using the same techniques applied to the emu material, this study found no morphological evidence of taste buds throughout the entire oropharynx and proximal oesophagus of $S$. camelus. Although this in itself is not necessarily indicative of an absence of taste in this species, it would suggest that taste buds, if present, are exceptionally few in number.

\section{Distribution}

As demonstrated in the present study, taste buds in D. novaehollandiae, when sectioned tangentially, were indistinguishable from the surrounding epithelium with H\&E staining. Taste buds are inherently difficult to identify in all bird species as they are obscured by the connective tissue papillae and the ducts of glands traversing the epithelium (Moore and Elliott 1946). Depending on the plane of sectioning, submucosal papillae and salivary ducts can also be mistaken for taste buds (Lindenmaier and Kare 1959). However, by using IHC labelling for neurofilament, it was possible to identify the presence of taste buds which had not been favourably sectioned, based on the demonstration of the accompanying nerve fibres positioned immediately beneath the structure (see Figs. 3,4 ). Although the neurofilament 
antibody is not specific to gustatory nerves, but to nerves in general, the combination of a particular grouping of epithelial cells distinct from glandular tissue, and the presence of sub-, peri- and intragemmal fibres supplying these cells, could only be indicative of taste buds. This staining technique, therefore, proved to be a more reliable method of accurately identifying taste buds in histological sections. However, despite employing this technique, no structures resembling taste buds were identified in S. camelus.

This study indicated that taste buds in $D$. novaehollandiae are present in the following non-keratinised regions of the oropharynx, namely the non-pigmented oropharyngeal roof and the non-pigmented oropharyngeal floor. Although two taste buds were identified in the proximal oesophagus, none were observed in the tongue root as previously reported (Crole and Soley 2009). This would imply that these structures are relatively scarce in these regions. Numerous studies have reported on the distribution of taste buds in birds (Berkhoudt 1985) and have demonstrated that these structures are located in the base of the tongue (tongue root) and the oropharyngeal roof and floor. Thus, the distribution of taste buds in $D$.

novaehollandiae appears to follow the general avian pattern although in this species their presence was restricted to the caudal aspect of the oropharynx. However, $D$. novaehollandiae is the only bird in which taste buds have been reported in the proximal oesophagus. Additionally, some birds possess taste buds in the keratinised regions of the oropharynx (which are usually more rostrally situated), including Upopa epops (Linnaeus 1758), Passer domesticus (Linnaeus 1758) (Botezat 1910) and Anas platyrhynchos (Linnaeus 1758) (Berkhoudt 1977), whereas Calidris species (Gerritsen et al. 1983) reportedly possess taste buds in the bill. The ability for chemoreception was identified in Calidris species (Gerritsen et al. 1983; van Heezik et al. 1983), based on feeding trials; however, physical taste buds were not demonstrated or their distribution determined.

\section{Structure}

An extensive collection of literature exists on the structure of the avian taste bud, and the earlier work has been summarised by Berkhoudt (1977). In general, the structural characteristics of taste buds in $D$. novaehollandiae resemble those of other birds (Bath 1906; Botezat 1910; Moore and Elliott 1946; Lindenmaier and Kare 1959; Gentle 1971b; Berkhoudt 1977; Ganchrow and Ganchrow 1985) particularly in respect of their ovoid shape and outer component of follicular cells. Although mammalian taste buds extend throughout all the layers of the stratified squamous epithelium in which they are housed (similar to that in birds), they differ in a number of respects. The outer layer of follicular cells is absent, only a single layer of elongated chemoreceptor (taste) cells and sustentacular (supporting) cells is present (Frappier 2006), and taste canals are not a feature of mammalian taste buds (Kudo et al. 2008). The taste buds of $D$. novaehollandiae and other birds, for example Anas platyrhynchos (Berkhoudt 1977), also differ in respect of the connective tissue sheath surrounding much of the taste bud, which displays a well-developed capillary supply. This would suggest that the avian taste bud as demonstrated in $D$. novaehollandiae occupies a deep, widened dermal papilla, thus partially isolating it from the surrounding epithelium. 
Based on the examination of taste buds from a number of avian species, Bath (1906) defined three distinct groups based on specific structural characteristics. Employing the criteria used by Bath (1906) [and summarised by Berkhoudt (1985)], the taste buds in $D$. novaehollandiae can be categorised as belonging to group I. These taste buds were ovoid in shape, and the receptor cells were enveloped by a peripheral sheath of follicular cells. The diameter of the taste buds in $D$. novaehollandiae $(51 \pm 7 \mu \mathrm{m})$ also places them within the range of those birds belonging to this group (Bath 1906), including G. domesticus (40-69 $\mu \mathrm{m})$ (Ganchrow and Ganchrow 1985). The length of the taste buds in many of the birds in group I (Bath 1906) was greater than that of $D$. novaehollandiae $(96 \pm 15 \mu \mathrm{m})$, although $G$. domesticus $(73-99 \mu \mathrm{m})$ and Columba livia (Linnaeus 1758) (78-109 $\mu \mathrm{m}$ ), also from this group, appeared to have a similar height (Bath 1906).

The taste pore in A. platyrhynchos [belonging to Group II (Bath 1906)] is divided into an outer pore $(100 \mu \mathrm{m})$ and an inner pore $(10 \mu \mathrm{m})$ (Berkhoudt 1977), similar to that noted in the present study. Although the inner pore in $D$. novaehollandiae $(10 \mu \mathrm{m})$ was comparable to that of $A$. platyrhynchos, the outer pore was only a quarter of the width $(25 \mu \mathrm{m})$. The small size of the outer pore in $D$. novaehollandiae may partially explain why these structures were not identified in previous studies using scanning electron microscopy (Crole 2009; Crole and Soley 2010b). Taste canals have been described in the taste buds of G. domesticus (Gentle 1971b; Kurosawa et al. 1983; Ganchrow and Ganchrow 1985, 1987) and Coturnix japonica (Linnaeus 1758) (Warner et al. 1967). Similar structures appeared to be present in some of the taste buds in $D$. novaehollandiae (see Fig. 5). A preliminary ultrastructural study using the 'pop-off' technique to section a $D$. novaehollandiae taste bud for TEM has confirmed that taste canals are present (Crole et al. 2013). These structures were identified by the presence of microvilli projecting into the taste canal from the light and dark cells lining the lumen (Crole et al. 2013).

A feature of the inner cell component of $D$. novaehollandiae taste buds was the presence of both light and dark elongated cells. Transmission electron microscopy (TEM) of taste buds in G. domesticus revealed light cells (gustatory cells displaying afferent synaptic contacts with axon terminals), dark cells (supporting cells displaying extensive axonal contacts with no synapses) and peripheral (follicular) cells (flattened cells with filaments and free ribosomes) (Kurosawa et al. 1983, cited by Berkhoudt 1985). Future ultrastructural studies on taste buds in $D$. novaehollandiae will be required to more accurately determine the structure of the light and dark cells observed by light microscopy in order to postulate their function. However, the scarcity of taste buds in the oropharynx of $D$. novaehollandiae will make the sampling of material for TEM technically challenging.

\section{Function}

The distribution of taste buds in A. platyrhynchos (Berkhoudt 1977) and G. domesticus (Ganchrow and Ganchrow 1985) has been linked to the particular feeding habits of these birds. Similarly, it would appear that the feeding method of $D$. novaehollandiae (Bonga Tomlinson 2000) can be linked to the particular distribution of taste buds in the caudo-dorsal region of the oropharynx. In this species, the tongue scrapes the oropharyngeal roof during retraction and swallowing (Bonga Tomlinson 2000), thus exposing the ingested food to the largest concentration of 
taste buds in the oropharynx. Whereas many studies have been performed in $G$. domesticus to determine the effect of taste on food intake (Gentle 1971a), relevant information of this nature remains unavailable for commercially exploited ratites such as $D$. novaehollandiae and $S$. camelus and should be the topic of future studies.

Evidence of a sense of taste in $S$. camelus has been addressed in a number of studies (Anon 1922; Brand and Gous 2006; Jackowiak and Ludwig 2008; Tivane 2008) and yielded only negative results (including the present study). However, the presence of chemoreception in the oropharynx of $S$. camelus, through mechanisms other than taste buds, has not been ruled out in the present study. For example, substances inactivating one or more enzymes in the oral mucosa may give rise to a characteristic sensation (Lindenmaier and Kare 1959). A well-developed bill tip organ is present in S. camelus and D. novaehollandiae (Crole and Soley 2014c), and there is little doubt that these birds display a high tactile acuity in their bill tips (Crole and Soley 2014b). Additionally, the median palatine and ventral ridges in the oropharynx of $S$. camelus, which both display a concentration of Herbst corpuscles (Crole and Soley 2014a), would contribute to this heightened sense of touch. S. camelus appears well equipped for selection of food by vision (Martin and Katzir 1995) and smell (Zelenitsky et al. 2011) as well as tactile discrimination (presence of a bill tip organ) (Crole and Soley 2014a).

\section{Acknowledgments}

The authors thank Dr A. Olivier (Klein Karoo Ostrich abattoir) and Ms. Tanya Claassen (Oryx Ostrich Abattoir) for providing S. camelus and D. novaehollandiae specimens; Mrs Charmaine Vermeulen for the photograph of the oropharynx; Ms. Erna van Wilpe from the Electron Microscope Unit, Department of Anatomy and Physiology; Dr S. Clift and Ms. R. Phaswane from the Department of Paraclinical Sciences, Faculty of Veterinary Science, University of Pretoria for the immunohistochemistry; the support staff of the Department of Anatomy and Physiology, Faculty of Veterinary Science, University of Pretoria. This work was funded by the University of Pretoria.

\section{References}

Anon THG (1922) Taste or scent in the ostrich. In: Ritchie J (ed) The Scottish naturalist. Oliver \& Boyd, Edinburgh, p 168. http://archive.org/stream/scottishnaturali1922arbr/ scottishnaturali1922arbr djvu.txt. Accessed 28 Aug 2013

Bancroft J, Gamble M (2002) Theory and practice of histological techniques, 5th edn. Churchill Livingston Elsevier, China

Bath W (1906) Die Geschmacksorgane der Vögel und Krokodile. Arch Biontol 1:5-47

Baumel JJ, King AS, Breazile JE, Evans HE, Vanden Berge JC (1993) Handbook of avian anatomy: Nomina Anatomica Avium, 2nd edn. Nuttall Ornithological Club, Cambridge

Berkhoudt H (1977) Taste buds in the bill of the mallard (Anas platyrhynchos L.). Their morphology, distribution and functional significance. Neth J Zool 27:301-331

Berkhoudt H (1985) Structure and function of avian taste buds. In: King AS, McLelland J (eds) Form and function in birds, vol 3. Academic Press, London, pp 463-491 
Bonga Tomlinson CA (2000) Feeding in paleognathous birds. In: Schwenk K (ed) Feeding: form, function, and evolution in tetrapod vertebrates. Academic Press, San Diego, pp 359394

Botezat E (1910) Morphologie, Physiologie und phylogenetische Bedeutung der Geschmacksorgane der Vögel. Anat Anz 36:428-461

Brand TS, Gous RM (2006) Feeding Ostriches. In: Bels V (ed) Feeding in domestic vertebrates: from structure to behaviour. CAB International, Wallingford, pp 136-155

Crole MR (2009) A gross anatomical and histological study of the oropharynx and proximal oesophagus of the emu (Dromaius novaehollandiae). Dissertation, University of Pretoria, Pretoria, South Africa

Crole MR, Soley JT (2009) Morphology of the tongue of the emu (Dromaius novaehollandiae). II. Histological features. Onderstepoort J Vet Res 76:347-361

Crole MR, Soley JT (2010a) Gross morphology of the intra-oral rhamphotheca, oropharynx and proximal esophagus of the emu (Dromaius novaehollandiae). Anat Histol Embryol $39: 207-218$

Crole MR, Soley JT (2010b) Surface features of the emu (Dromaius novaehollandiae) tongue. Anat Histol Embryol 39:355-365

Crole MR, Soley JT (2011) Gland distribution and structure in the oropharynx and proximal oesophagus of the emu (Dromaius novaehollandiae). Acta Zool-Stockholm. 92:206-215

Crole MR, Soley JT (2014a) Comparative distribution and arrangement of Herbst corpuscles in the oropharynx of the ostrich (Struthio camelus) and emu (Dromaius novaehollandiae). Anat $\operatorname{Rec} 297: 1338-1348$

Crole MR, Soley JT (2014b) Comparative morphology, morphometry and distribution pattern of the trigeminal nerve branches supplying the bill tip in the ostrich (Struthio camelus) and emu (Dromaius novaehollandiae). Acta Zool-Stockholm, (in press)

Crole MR, Soley JT (2014c) The enigmatic bill tip organ of the ostrich and emu. In: Programme of the Theo Murphy international scientific meeting - when senses take flight: the evolution, development, mechanisms and function of avian senses, Buckinghamshire, England

Crole MR, Soley JT, van Wilpe E (2013) Distribution and structure of taste buds in the emu. Proc Microsc Soc S Afr 43:7

Crole MR, du Plessis L, Soley JT (2015) Morphological features of Herbst corpuscles in the oropharynx of the ostrich (Struthio camelus) and emu (Dromaius novaehollandiae). Anat Rec 298:783-796

Feder F-H (1972) Zur mikroskopischen Anatomie des Verdauungsapparates beim Nandu (Rhea americana). Anat Anz 132:250-265

Frappier BL (2006) Digestive System. In: Eurell J-A, Frappier BL (eds) Dellmann's textbook of veterinary histology, 6th edn. Blackwell Publishing, Ames, pp 170-211

Ganchrow D, Ganchrow JR (1985) Number and distribution of taste buds in the oral cavity of hatchling chicks. Physiol Behav 34:889-894 
Ganchrow JR, Ganchrow D (1987) Taste bud development in chickens (Gallus gallus domesticus). Anat Rec 218:88-93

Ganchrow D, Ganchrow JR (1989) Gustatory ontogenesis in the chicken; an avianmammalian comparison. Med Sci Res 17:223-228

Gentle MJ (1971a) Taste and its importance to the domestic chicken. Brit Poult Sci 12:77-86

Gentle MJ (1971b) The lingual taste buds of Gallus domesticus. Brit Poultry Sci 12:245-248

Gerritsen AFC, van Heezik YM, Swennen C (1983) Chemoreception in two further Calidris species (C. maritime and $C$. canutus) with a comparison of the relative importance of chemoreception during foraging in Calidris species. Neth J Zool 33:485-496

Gussekloo SWS, Bout RG (2005) The kinematics of feeding and drinking in palaeognathous birds in relation to cranial morphology. J Exp Biol 208:3395-3407

Jackowiak H, Ludwig M (2008) Light and scanning electron microscopic study of the structure of the ostrich (Strutio camelus) tongue. Zool Sci 25:188-194

Kudo K, Nishimura S, Tabata S (2008) Distribution of taste buds in layer-type chickens: scanning electron microscopic observations. Anim Sci J 79:680-685

Kurosawa T, Niimura S, Kusuhara S, Ishida K (1983) ニワトリ味蕾の形態学的研究 (Morphological studies of taste buds in chickens). Jpn J Zootech Sci 54:502-510

Latham J (1790) Index Ornithologicus, Sive Systema Ornithologiae: Complectens Avium Divisionem In Classes, Ordines, Genera, Species, Ipsarumque Varietates: Adjectis Synonymis, Locis, Dexdriptionibus, \&c, Vol. 2. Leigh Et Sotheby, London, 920 pp

Lindenmaier P, Kare MR (1959) The taste end-organs of the chicken. Poult Sci 38:545-549

Linnaeus C (1758) Systema naturae per regna tria naturae, secundum classes, ordines, genera, species, cum characteribus, differentiis, synonymis, locis. 10th edn. Tomus 1. L. Salvii (ed) Stockholm, Sweden

Martin GR, Katzir G (1995) Visual fields in ostriches. Nature 374:19-20

McCann C (1973) The tongues of kiwis. Notornis 20:123-127

Moore DA, Elliott R (1946) Numerical and regional distribution of taste buds on the tongue of the bird. J Comp Neurol 84:119-131

Roura E, Baldwin MW, Klasing KC (2013) The avian taste system: potential implications in poultry nutrition. Anim Feed Sci Tech 180:1-9

Saito I (1966) Comparative anatomical studies of the oral organs of the poultry. V. Structure and distribution of taste buds of the fowl. Bull Fac Agric Miyazaki Univ 13:95-102

Santos TC, Fukuda KY, Guimarães JP, Oliveira MF, Miglino MA, Watanabe I-S (2011) Light and scanning electron microscopy study of the tongue in Rhea americana. Zool Sci 28:41-46

Tivane C (2008) A morphological study of the oropharynx and oesophagus of the ostrich (Struthio camelus). Dissertation, University of Pretoria, Pretoria, South Africa 
Van Heezik YM, Gerritsen AFC, Swennen C (1983) The influence of chemoreception on the foraging behaviour of two species of sandpiper, Calidris alba and Calidris alpina. Neth J Sea Res 17:47-56

Warner RL, McFarland LZ, Wilson WO (1967) Microanatomy of the upper digestive tract of the Japanese quail. Am J Vet Res 28:1537-1548

Zelenitsky D, Therrien F, Ridgely RC, McGee AR, Witmer LM (2011) Evolution of olfaction in non-avian theropod dinosaurs and birds. Proc R Soc B 278:3625-3634 